\title{
Design and development of a forced flow type dryer for medicinal and aromatic crops
}

\section{DAWN C.P. AMBROSE, S. J. K. ANNAMALAI AND RAVINDRA NAIK}

Received : 26.12.2014; Revised : 11.03.2016; Accepted : 23.03.2016

See end of the Paper for authors' affiliation

Correspondence to :

\section{DAWN C.P. AMBROSE}

Central Institute of Agricultural Engineering, Regional Centre, COIMBATORE (T. N.) INDIA Email : dawncp@yahoo.com
- Abstract : Medicinal and aromatic crops like curry leaf, patchouli, senna etc. are traditionally dried under sun resulting in inferior quality produce. In order to achieve better drying in terms of quality and drying time, an attempt was made to design and develop a mechanical dryer of forced flow type based on preliminary laboratory studies on drying curry leaf. The overall dimension of the dryer was $900 \times 900 \times 16500 \mathrm{~mm}$. The dryer consists of a drying chamber, plenum chamber, heating chamber and a blower driven by $2 \mathrm{HP}$ motor. The performance of the dryer was evaluated for drying curry leaves. Moisture content of curry leaves decreased from about 67 per cent to about 5 per cent (w.b.) in approximately 6 hours for drying $50 \mathrm{~kg}$ of fresh curry leaf. The thermal efficiency of the dryer was found to be 45.6 per cent and the heat utilisation factor was 0.32 . The quality of the dried curry leaf in terms of volatile oil content, colour and rehydration ratio was found to be good.

- KEY WORDS : Forced flow dryer, Design, Development, Drying, Curry leaf, Performance, Quality

- HOW TO CITE THIS PAPER : Ambrose, Dawn C.P., Annamalai, S.J.K. and Naik, Ravindra (2016). Design and development of a forced flow type dryer for medicinal and aromatic crops. Internat. J. Agric. Engg., 9(1) : 102-108. 